Research Article

\title{
Dynamic Response Analysis of Underground Double-Line Tunnel under Surface Blasting
}

\author{
Pei Zhang $\left(\mathbb{D},{ }^{1}\right.$ Jianhua Cai, ${ }^{2}$ Feng Zong, ${ }^{3}$ Yanpeng He $\mathbb{D},{ }^{1}$ and Qiong Wang ${ }^{4}$ \\ ${ }^{1}$ College of Energy Science and Engineering, Xi'an University of Science and Technology, Xi'an, Shanxi 710000, China \\ ${ }^{2}$ Pingliang Xin'an Coal Industry Co., Ltd., Pingliang, Gansu 744000, China \\ ${ }^{3}$ Shaanxi Jinyuan Zhaoxian Mining Co., Ltd., Baoji, Shanxi 721000, China \\ ${ }^{4}$ Department of Emergency Technology and Management, North China Institute of Science and Technology, Beijing 101601, China
}

Correspondence should be addressed to Pei Zhang; zhangpei@xust.edu.cn

Received 19 June 2021; Accepted 18 July 2021; Published 30 July 2021

Academic Editor: Yun Lin

Copyright (C) 2021 Pei Zhang et al. This is an open access article distributed under the Creative Commons Attribution License, which permits unrestricted use, distribution, and reproduction in any medium, provided the original work is properly cited.

\begin{abstract}
Blasting has been widely used for economical and rapid rock excavation in civil and mining engineering. In order to study the influence of relative horizontal distance and relative vertical distance between two tunnels on the dynamical response of the two tunnels, 10 numerical simulation cases are done by LS-DYNA 3D models under surface explosion by controlling the clear distance and height difference of double-line tunnel, and the ALE multimaterial fluid structure coupling algorithm is applied to analyze the dynamic response characteristics of double-line tunnel under different conditions. The numerical results show that the dynamic response characteristics of the tunnel lining are affected by the change of the clear distance and height difference of the tunnel. With the increase of the height difference between adjacent tunnels, the peak value of vibration velocity at the top of the lining on the blast face increases, which is due to the upward elevation of the right tunnel, which is more conducive to the reflection and superposition of stress waves. When the height difference of tunnel is $4-6 \mathrm{~m}$, the vibration velocity and displacement of monitoring point $\mathrm{C}$ on the back blasting side will change abruptly, and the variation range of vibration velocity is about $25 \%$, while the variation range of displacement is about $60 \%$.
\end{abstract}

\section{Introduction}

Blasting is widely used in rock excavation, mining, and other hard rock engineering applications since it has the advantages of strong geological adaptability and economy. However, the blast-induced vibration may do harm to the surrounding buildings, tunnels, and other structures. At present, many studies have been done for blasting-induced damage or effects on surface buildings, while the research studies on underground structures are quite rare relatively. With the increase of underground space building, the underground tunnel engineering are booming and face lots of blasting problems, such as tunnel rock fall. Therefore, it is very important to study how to effectively protect underground structures and minimize the loss under the strong explosion.

Many scholars have done research on the dynamic response characteristics of underground structures under explosive loading. Eitzenberger [1] observed through experimental and numerical investigations that the attenuation of the shock wave is controlled by the texture of the rock mass. Wu et al. [2] investigated the propagation of blastinduced shock wave in jointed rock mass using accelerometers and found that the attenuation of the shock wave is completely dependent on the distance from the charge weight, the angle between the strike of rock strata, and the direction of wave propagation. Yang et al. [3] investigated the response of blast-induced vibration on tunnel surfaces and inside surrounding rock using three-dimensional (3D) numerical analysis procedure. Numerical studies show that compared with the inside vibration, the tunnel surface vibration has a higher, more readily attenuated PPV and a lower frequency with a slower rate of decline in the dominant frequency. Liang et al. [4] investigated the response of an existing tunnel subjected to blast-induced vibrations 
from a newly constructed tunnel placed adjacent to the existing tunnel. Mohammad and Rehan Sadique [5] considered an internal blast loading on a rock tunnel constructed in quartzite rock; the results show that the extent of damage in shallow depth tunnels is found to be more than that of the tunnels at higher depth of overburden. Liu et al. [6] investigated the explosion inside tunnel and a formula for the explosion blast wave overpressure at a certain distance from the detonation center point inside the tunnel was derived by using the dimensional analysis theory. Feldgun et al. [7] studied internal blast loading in a buried lined tunnel by the modified Godunov method, which considered all the stages of the process: detonation of the internal charge; the shock wave propagation in the internal gas and its following interaction with the cavity's shell lining including multiple reflections. Yang et al. [8] performed numerical modeling to assess the damage characteristics of an underwater tunnel subjected to blast loads and explore the potential mitigation measures based on coupled Lagrange and Euler (CLE) method. The results show that the rigidity and load-carrying ability of the tunnel are significantly improved by bonding the CFRP cloth. The recommended thickness of the CFRP cloth is $0.5-0.835 \mathrm{~mm}$. Koneshwaran et al. [9] investigated underground transport tunnels in blast loading; the results indicated that several bolts failed in the longitudinal direction due to redistribution of blast loading to adjacent tunnel rings, and the tunnel segments respond as arch mechanisms in the transverse direction and suffered damage mainly due to high bending stresses.

The above researches are of great significance to understand the mechanism and process of underground space dynamic disaster. However, the researches on the dynamic response characteristics of underground double-line tunnel under the surface blasting are relatively rare. The research on the structures under explosive loading mainly adopts the methods of experiment, theoretical analysis, and numerical simulation. The explosion experiment is the most effective and direct method to study the dynamic response characteristics of the structures, but the destructive experimental conditions are harsh and costly. Under the blast impact load, the underground structure is not only affected by the stress waves from all directions, but also influenced by the nonperiodic transient action and considering the plastic strain of the material, which makes the problem become a highly nonlinear problem combining state nonlinearity and material nonlinearity [10-14]. Therefore, it is difficult to realize the blast mechanics analysis of complex structures by theoretical means. For these reasons, the use of numerical method to study the complex progress between wave propagation and tunnel interaction is necessary and effective. In this paper, in order to study the influence of relative horizontal distance and relative vertical distance between two tunnels on the dynamical response of the two tunnels, 10 numerical simulation cases are done by LS-DYNA 3D models under surface explosion. The research results can provide a useful reference for the antiexplosion protection design of underground tunnel.

\section{Three-Dimensional Finite Element Modeling}

2.1. Finite Element Modeling of Rock and Lining. In order to study the influence of relative horizontal distance and relative vertical distance between two tunnels on the dynamical response of the two adjacent tunnels, 10 numerical simulation cases are done by LS-DYNA 3D models under surface explosion. The model is constructed in $\mathrm{cm}-\mathrm{g}-\mu$ s unit system. Figure 1 shows the geometric model of the double-line tunnel. Figures 2 and 3 are the isometric side view and front view of the finite model of the double-line tunnel, respectively. The size of whole model is $80 \mathrm{~m} \times 10 \mathrm{~m} \times 42 \mathrm{~m}$. The outer diameter of the lining is $10 \mathrm{~m}$, the wall thickness of the lining is $0.3 \mathrm{~m}$, and the longitudinal length of the lining is $10 \mathrm{~m}$. The charge of the TNT explosive is $40 \mathrm{~kg}$. The distance between the side and top of the left lining and the center of TNT explosive is $30 \mathrm{~m}$ and $20 \mathrm{~m}$, respectively, as shown in Figure 1. Three degrees of freedom (UX, UY, and UZ) of the bottom of the finite element model are constrained. In order to simulate the infinite region and eliminate the influence of the reflected stress wave on the simulation results, except for the top free surface, the other boundary segment of the model is controlled by keyword *Boundary_Non_Reflecting, which can absorb the expansion wave and shear wave passing through the interface.

Considering the influence of lining clear distance and height difference on dynamic response characteristics of double line tunnel under surface blasting, the following parametric analysis scheme is formulated. When analyzing the influence of lining clear distance variable on dynamic characteristics, ensure that the height difference of two linings is $0 \mathrm{~m}$, the position of left lining relative to TNT explosive remains unchanged at the same time, only change the horizontal clear distance of right lining, and the horizontal clear distances of lining are $5 \mathrm{~m}, 7 \mathrm{~m}, 9 \mathrm{~m}, 11 \mathrm{~m}$, and $13 \mathrm{~m}$, respectively. In order to simplify the subsequent analysis, the corresponding conditions are marked as A1, A2, A3, A4, and A5, respectively, as shown in Figure 4 and Table 1. When analyzing the influence of lining height difference variables on dynamic characteristics, the horizontal clear distance between two linings is $9 \mathrm{~m}$, and the position of left lining relative to TNT explosive remains unchanged. The height differences between two linings are $0 \mathrm{~m}, 2 \mathrm{~m}, 4 \mathrm{~m}, 6 \mathrm{~m}$, and $8 \mathrm{~m}$, respectively. In order to simplify the subsequent analysis, the corresponding conditions are marked as A3, B3, C3, D3, and E3, respectively, as shown in Figure 4 and Table 1 .

2.2. ALE Multimaterial Fluid Structure Coupling Algorithm. The Arbitrary Lagrange-Euler (ALE) coupling algorithm is used in LS-DYNA 3D to solve the fluid structure coupling problem in this paper, which is the same as the description of Euler algorithm. It can be understood that there are two layers of grids overlapped together, but the difference is that the grid in ALE algorithm is not fixed and can move arbitrarily in space. The ALE algorithm first performs several Lagrange time step calculations, in which the element mesh deforms with the material flow and then performs ALE time 


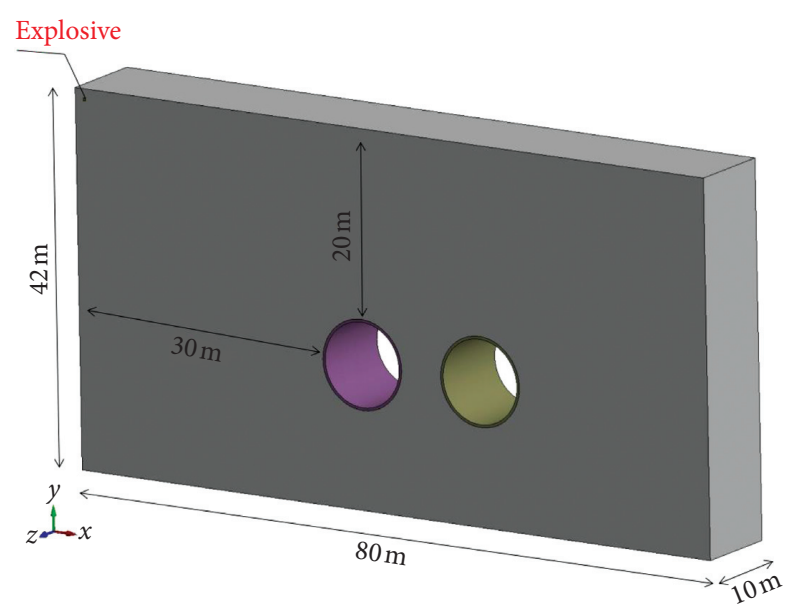

Figure 1: Isometric side view of geometric model.

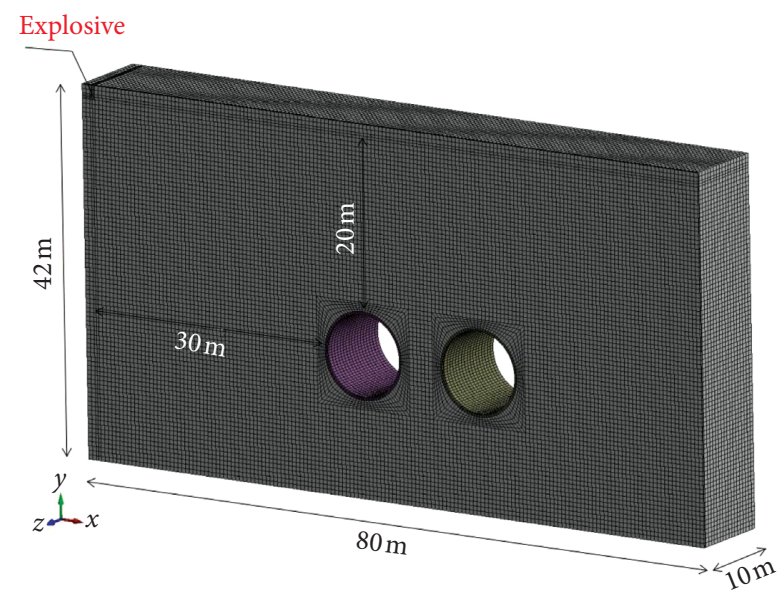

Figure 2: Equiaxed side view of finite element model.

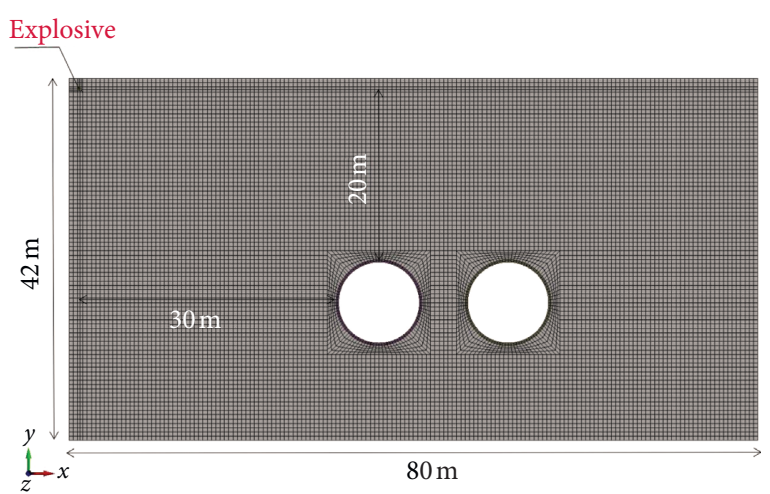

Figure 3: Front view of finite element model.

step calculation. (1) The boundary conditions of the modified object remain unchanged, and the internal element is meshed to keep the topological relationship of the mesh unchanged. This step is called smooth step. (2) The element parameters (density, energy, stress tensor, etc.) and node velocity vector in the deformed mesh are transferred to the new mesh, which is called expectation step. ALE algorithm on the one hand retains the advantages of Lagrange

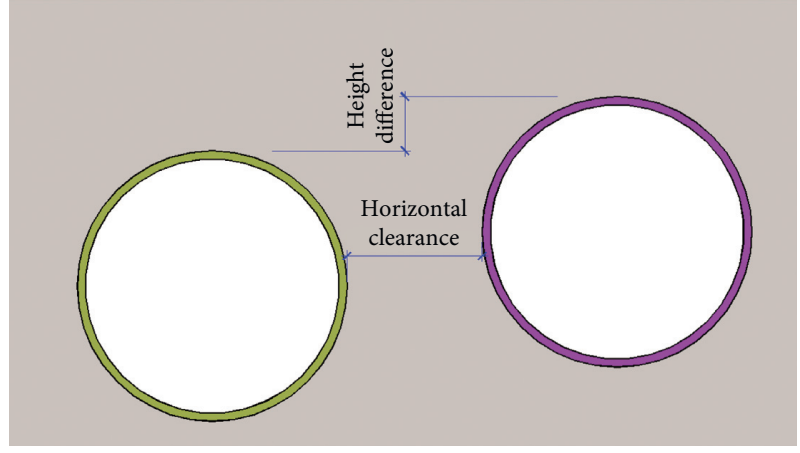

FIGURE 4: Details of numerical simulation cases.

algorithm $[10,15,16]$; that is, it can accurately detect the boundary of the mesh, but also inherits the main advantages of Euler algorithm, which can well solve the problem of element distortion, make up for the shortcomings of the two algorithms, and is very suitable for large deformation analysis.

In this simulation, the rock mass and lining are described by the Lagrange method; the explosive and air are described by the Euler method. This method couples fluid and solid together to realize the nonlinear coupling between fluid medium and rock mass model by keyword *Constrained_Lagrange_In_Solid. The fluid structure coupling algorithm is to couple the structure and fluid together through certain constraint method to realize the transmission of mechanical parameters. The main constraint methods [17] are velocity constraint, acceleration constraint, and penalty function constraint. The advantage of this algorithm is that the fluid element and structural element on the coupling surface do not need to be corresponded one by one, which greatly reduces the workload of mesh generation. The calculation steps of velocity and acceleration constraints are as follows:

The fluid element with structural nodes is searched, and the structural node parameters (mass, momentum, and nodal force) are assigned to the fluid element nodes.

$$
m_{n}(M, F)_{f, i}=m_{0}(M, F)_{f, i}+h_{i} m(M, f)_{s} .
$$

Calculate the new acceleration of fluid node (velocity):

$$
a(v)_{f, i}=\frac{F(M)_{f, i}}{m_{f n, i}} .
$$

The acceleration (velocity) of constrained structure node is as follows:

$$
a(v)_{s}=\sum_{1}^{i} h_{i} a(v)_{f, i} \text {, }
$$

where $m_{n}$ and $m_{o}$ represent the nodal mass of fluid element before and after distribution, respectively; $M$ and $F$ are the momentum and nodal force, respectively; $a$ and $v$ are the acceleration and velocity of the node; $h$ is the number of nodes contained in a single fluid element; and $f$ and $s$ are symbols of fluid and solid element. 
TABLE 1: Details of numerical simulation cases.

\begin{tabular}{lccc}
\hline $\begin{array}{l}\text { Numerical simulation case } \\
\text { number }\end{array}$ & $\begin{array}{c}\text { Horizontal clearance of lining } \\
(\mathrm{m})\end{array}$ & $\begin{array}{c}\text { Numerical simulation case } \\
\text { number }\end{array}$ & Height difference of lining (m) \\
\hline A1 & 5 & A3 & 0 \\
A2 & 7 & B3 & 2 \\
A3 & 9 & C3 & 4 \\
A4 & 11 & D3 & 6 \\
A5 & 13 & E3 & 8 \\
\hline
\end{tabular}

\subsection{Constitutive Model of Materials}

2.3.1. Constitutive Model of TNT Explosive. Explosive material model is described by keyword *MAT_HIGH_EXPLOSIVE_BURN combined with JWL equation of state provided by LS-DYNA. The $P-V$ relation of the JWL equation of state is as follows:

$$
P=A\left(1-\frac{\omega}{R_{1} V}\right) e^{-R_{1} V}+B\left(1-\frac{\omega}{R_{2} V}\right) e^{-R_{2} V}+\frac{\omega E}{V},
$$

where $A, B, R_{1}, R_{2}$, and $\omega$ are material constants for TNT explosive, parameters $A$ and $B$ represent the magnitudes of pressure, $\rho$ is the density of the explosive, and $E$ is the specific internal energy at atmospheric pressure.

For TNT explosive [18], $\rho=1630 \mathrm{~kg} / \mathrm{m}^{3}$; detonation wave speed $D=6930 \mathrm{~m} / \mathrm{s}$; Chapman-Jouget pressure PCJ = $0.255 \times 10^{11} \mathrm{~Pa} ; A=373800 \mathrm{MPa} ; B=3747 \mathrm{MPa} ; R_{1}=4.15$; $R_{2}=0.9$; and $\omega=0.35$.

2.3.2. Constitutive Model of Air. The air model [19] is described by keyword *MAT_NULL combined with multilinear equation of state *EOS_LINEAR_POLYNOMIAL in this study.

$$
P=\left[C_{0}+C_{1} \mu+C_{2} \mu^{2}+C_{3} \mu^{2}\right]+\left[C_{4}+C_{5} \mu+C_{6} \mu^{2}\right] e .
$$

For the convenience of calculation, air is regarded as an ideal gas, in which the parameters are as follows: $C_{0}=C_{1}=C_{2}=C_{3}=C_{6}=0, C_{4}=C_{5}=0.4$. For air in cm-g- $\mu \mathrm{s}$ unit system, the parameters of the null material model are as follows: density $\rho=0.0012 \mathrm{~g} / \mathrm{cm}^{3}$ and dynamic viscosity coefficient $M u=0.001$.

2.3.3. Constitutive Model of Concrete. The concrete material adopts the model which adapts to high pressure and high strain rate by means of keyword *MAT_JOHNSON_HOLMQUIST_CONCRETE (HJC). The material model of HJC consists of state equation, yield equation, and damage equation. The equation of state can be divided into elastic stage, plastic stage (internal porosity compression, porosity reduction), and fully dense stage (internal porosity compression, damage, and fine grain cracks). The characteristic of the HJC model is that it can reflect the dynamic response of brittle materials such as concrete under large strain, high strain rate and high pressure, and material damage effect. It is especially suitable for the study of dynamic response of concrete structure under explosion load. The equations of state of HJC material model are as follows.

Elastic loading and unloading $\left(p<p_{c}\right)$ is given by

$$
p=k_{e} \mu \text {. }
$$
by

Loading of plastic transition zone $\left(p_{\mathrm{c}} \leq p \leq p_{1}\right)$ is given

$$
p=p_{1}+\frac{\left(p_{1}-p_{c}\right)\left(\mu-\mu_{1}\right)}{\mu-\mu_{1}}
$$

Unloading of plastic transition zone $\left(p_{c} \leq p \leq p_{1}\right)$ is given by

$$
p-p_{\max }=\left[\left(1-\frac{\mu_{\max }-\mu_{c}}{\mu_{1}-\mu_{c}}\right) K_{e}+\frac{\mu_{\max }-\mu_{c}}{\mu_{1}-\mu_{c}} K_{1}\right]\left(\mu-\mu_{\max }\right) \text {. }
$$

Fully compacted loading $\left(p>p_{1}\right)$ is given by

$$
p=k_{1} \frac{\mu-\mu_{1}}{1+\mu_{1}}+k_{2}\left(\frac{\mu-\mu_{1}}{1+\mu_{1}}\right)^{2}+k_{3}\left(\frac{\mu-\mu_{1}}{1+\mu_{1}}\right)^{3} \text {. }
$$

In the fully compacted unloading $\left(p>p_{1}\right)$ stage, the material is completely destroyed:

$$
p-p_{\max }=k_{1}\left(\frac{\mu-\mu_{1}}{1+\mu_{1}}-\left(\frac{\mu-\mu_{1}}{1+\mu_{1}}\right)_{\max }\right) \text {. }
$$

The yield equation of HJC material model is as follows:

$$
\sigma^{*}=\left[\mathrm{A}(1-D)+B P^{* N}\right]\left(1+C \ln \varepsilon^{*}\right) .
$$

The damage equation of HJC material model is as follows:

$$
D=\sum \frac{\Delta \varepsilon_{p}+\Delta \mu_{p}}{D_{1}\left(P^{*}+T^{*}\right)^{D_{2}}}
$$

where $k_{e}=p_{c} / \mu_{c}$ is the bulk modulus, which is the ratio of crushing volume pressure $p_{c}$ and crushing volume $\mu_{c}$ strain in uniaxial compression test, $p_{1}$ represents compaction pressure of concrete material, and $\mu_{1}$ is the compaction volume strain. $K_{1}$ is the plastic bulk modulus; $p_{\max }$ and $\mu_{\max }$ are the maximum volume pressure and volume strain before unloading. In this stage, the porosity in the material is compressed, the material is damaged, and the crushing crack begins to appear; $\sigma^{*}$ is the standardized equivalent stress, $D$ is the damage value $(0 \leq D \leq 1.0), p^{*}$ is the standardized hydrostatic pressure, $\varepsilon^{*}=\left(\varepsilon / \varepsilon_{0}\right)$ is the dimensionless strain rate, $A$ is the normalized cohesive strength; $B$ is the normalized pressure hardening coefficient; $N$ is the pressure 
hardening index; $C$ represents the strain rate coefficient; $\Delta \varepsilon_{p}$ and $\Delta \mu_{p}$ are the equivalent plastic strain increment and plastic volume strain increment of an element in a calculation cycle, $T^{*}$ is the standardized maximum tensile stress, and $D_{1}$ and $D_{2}$ are the damage constant of the concrete. The parameters of concrete in this study are shown in Table 2.

2.3.4. Constitutive Model of Rock. The rock is simulated by means of the Drucker-Prager model. The yield criteria of the Drucker-Prager model are given by

$$
\begin{aligned}
t-p \cdot \tan \beta-d & =0, \\
t & =\left(\frac{q}{2}\right)\left\{a-b\left(\frac{r}{q}\right)^{3}\right\}, \\
a & =\frac{1+1}{K}, \\
b & =\frac{1-1}{K},
\end{aligned}
$$

where $p$ is hydrostatic stress, $q$ represents von Mises stress, and $K$ is a scalar parameter that determines the shape of the yield surface and maintains the convexity of the yield surface in the deviatoric $(p)$ plane. $r$ is the third invariant of the deviatoric stress tensor:

$$
r=\left(\frac{27 J_{3}}{2}\right)^{1 / 3}
$$

where $J_{2}$ and $J_{3}$ represent the second and the third deviatoric stress invariants, respectively.

$$
\begin{aligned}
\tan \beta & =\frac{6 \sin \varphi}{(3-\sin \varphi)}, \\
d & =\frac{6 C \cos \varphi}{(3-\sin \varphi)}
\end{aligned}
$$

where $\varphi$ is the angle of friction and $C$ is the dilation angle.

The material properties used for quartzite rock mass are given in Table 3, obtained from triaxial test [21].

\section{Dynamic Response Characteristics of Double- Line Tunnel during Surface Blasting}

3.1. Propagation Law of Stress Wave in Double-Line Tunnel. Figure 5 shows the pressure nephogram of rock mass under A1 condition. At the moment of TNT explosive explosion, the explosive volume expands rapidly in a very short time and rapidly changes from solid state to high-pressure gas state. The high-pressure gas acts on the rock and produces stress wave $(t=0.5 \mathrm{~ms})$ on the rock mass, with the peak pressure of about $228 \mathrm{MPa}$. Due to the nonreflective boundary condition, the shock wave will not be reflected at the rock mass boundary. With the further propagation and diffusion of the shock wave in the rock mass, the amplitude of the stress wave is greatly weakened. When $t=6.3 \mathrm{~ms}$, the peak value of the pressure decreases to about $4.32 \mathrm{MPa}$. Combined with Figure $5(t=10 \mathrm{~ms}, t=17 \mathrm{~ms}$, and the velocity time history curve of lining monitoring points in Figure 6), at $t=10 \mathrm{~ms}$, the stress wave propagates to the left lining, and at $t=17 \mathrm{~ms}$, the stress wave propagates to the right lining. With the further attenuation of the shock wave, the stress wave gradually becomes elastic wave, which propagates at the elastic wave speed which does not disturb the physical state of the rock mass.

It can also be seen from Figure 7 that the peak velocity of monitoring point $\mathrm{A}$ is about $7.5 \mathrm{~cm} / \mathrm{s}$ at $t=27 \mathrm{~ms}$, and the time from stress wave propagation to monitoring point $A$ to reaching the peak velocity of monitoring point $\mathrm{A}$ is about $17 \mathrm{~ms}$. The peak velocity of point $B$ is about $6.4 \mathrm{~cm} / \mathrm{s}$ at $t=46 \mathrm{~ms}$, and the time from stress wave propagation to point $B$ to the peak velocity is about $29 \mathrm{~ms}$. It can be seen that the time course of reaching the peak speed is different, and the time difference is about $12 \mathrm{~ms}$. This is because the stress wave produces a series of reflection and diffraction between two tunnels, so its dynamic response process is different from that of a single tunnel. In view of this, this paper starts the follow-up research, that is, by changing the horizontal spacing and height difference of the tunnel to investigate the dynamic response characteristics of the double-line tunnel under the surface explosion load.

\subsection{Distribution Law of Equivalent Stress of Lining.}

Figures 8 and 9 show the equivalent stress nephogram of concrete lining under different conditions (considering horizontal clear distance and height difference) at the same time $(t=20 \mathrm{~ms})$, respectively. For the tunnel on the left, the stress distribution on the left side of YOZ symmetry plane of the lining is basically the same. For the right side of the YOZ symmetry plane of the lining, the stress distribution shows obvious differences. According to the color corresponding to the cloud figure, the darker the color of the element is, the smaller the equivalent stress is. It can be seen from Figure 8 that with the increase of the clear distance of the lining $(5 \mathrm{~m}$, $7 \mathrm{~m}, 9 \mathrm{~m}, 11 \mathrm{~m}$, and $13 \mathrm{~m}$ ), the stress on the right side of the symmetry plane of YOZ of the lining is not regularly decreasing. It can be seen that under A3 and A4 conditions, the overall value of the equivalent stress in this area is obviously smaller than the other three conditions (A1, A2, and A5). This shows that the influence of the tunnel spacing on the dynamic response characteristics of the lining is not linear. Similarly, it can be seen in Figure 9 that the dynamic response characteristics of the lining also show a nonlinear relationship with the variation of the lining height difference $(0 \mathrm{~m}, 2 \mathrm{~m}, 4 \mathrm{~m}, 6 \mathrm{~m}$, and $8 \mathrm{~m})$.

3.3. Parameter Analysis of Monitoring Points. Figure 10 is the layout of monitoring points for the left lining. Monitoring points $\mathrm{A}, \mathrm{B}, \mathrm{C}$, and $\mathrm{D}$ are all located on the left lining. Figure 11 shows the relationship curve between the velocity of the monitoring point and the horizontal clear distance of the tunnel. It can be seen from Figure 11 that the velocity response of the monitoring point at the top of the lining blast facing surface is lower than that of the side wall under the action of explosion load. Taking the clear distance of the lining as an example, the peak vibration velocity of the 
TABLE 2: Concrete properties [20].

\begin{tabular}{lccccccc}
\hline Mid & Ro $\left(\mathrm{g} / \mathrm{cm}^{3}\right)$ & $G$ (Mbar) & $A$ & $B$ & $C$ & $N$ & $F c(\mathrm{Mbar})$ \\
\hline & 2.4 & 0.114 & 0.79 & 1.6 & 0.007 & 0.61 & $3.00 E-04$ \\
$T$ (Mbar) & $E p s 0$ & $E f m i n$ & $S f m a x$ & $P c(\mathrm{Mbar})$ & $U c(\mathrm{Mbar})$ & $P l(\mathrm{Mbar})$ & $u l$ \\
$4.00 E-05$ & $1.00 E-06$ & 0.01 & 7 & $1.60 E-04$ & 0.001 & 0.008 \\
$D_{1}$ & $D_{2}$ & $K_{1}$ (Mbar) & $K_{2}$ (Mbar) & $K_{3}(\mathrm{Mbar})$ & $f s$ & 0.1 \\
0.04 & 1 & 0.85 & -1.71 & 2.08 & 0.3 & \\
\hline
\end{tabular}

TABLe 3: Quartzite rock properties [21].

\section{Description}

Weathering condition

Specific gravity $(G)$

Density $(\rho)\left(\mathrm{kg} / \mathrm{m}^{3}\right)$

Elastic modulus $(E)(\mathrm{GPa})$

Poisson's ratio $(\nu)$

Angle of internal friction $(\varphi)$

In situ stress ratio $\left(K_{0}\right)$

Dilation angle $(\psi)$

Cohesion $(c)(\mathrm{MPa})$

$\sigma_{c}(\mathrm{MPa})$

RQD range

RMR
Quartzite rock

Slightly to moderately

2.65

2550

28

0.25

$45^{\circ}$

0.5

$5^{\circ}$

2.3

40

$75-80$

47

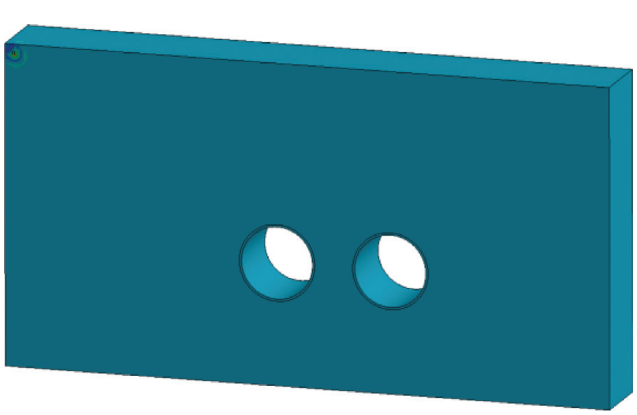

(a)

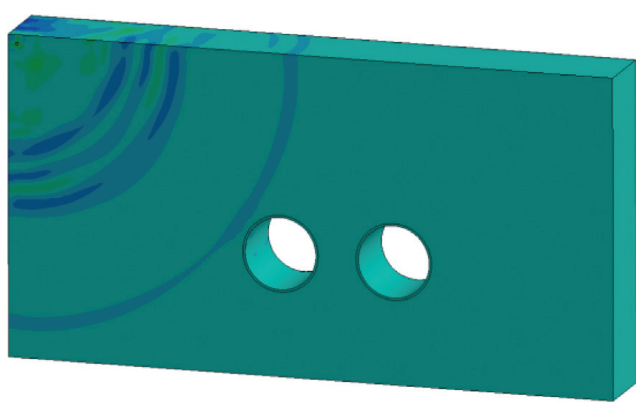

(c)
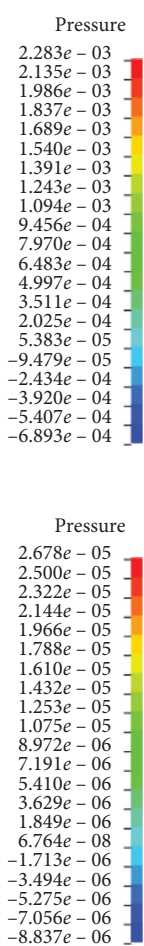
$-7.056 e-06$
$-8.837 e-06$

(n)

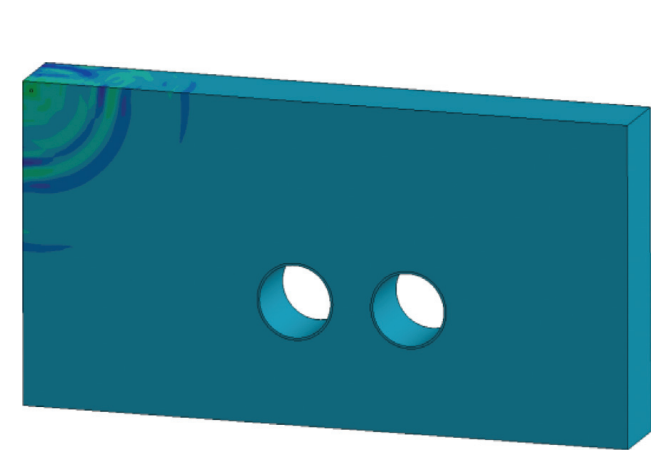

Pressure

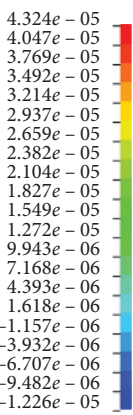

(b)
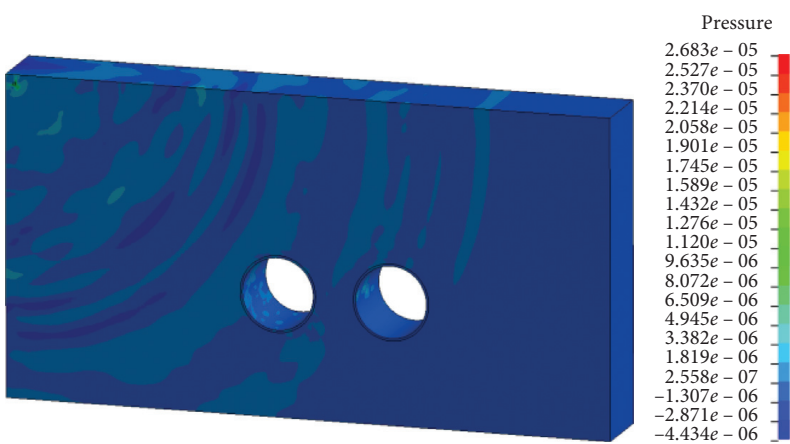

(d)

Figure 5: Nephogram of geotechnical pressure at typical time (Mbar). (a) $T=0.5 \mathrm{~ms}$. (b) $T=6.3 \mathrm{~ms}$. (c) $T=10 \mathrm{~ms}$. (d) $T=17 \mathrm{~ms}$.

monitoring point $\mathrm{B}$ at the top of the lining blast facing surface is about $7.5 \mathrm{~cm} / \mathrm{s}$, and the peak vibration velocity of the monitoring point $\mathrm{A}$ at the side wall of the lining blast facing surface is about $6.5 \mathrm{~cm} / \mathrm{s}$. The vibration velocity is about $13 \%$ lower than that of B. At the same time, it can be seen that the peak velocity of monitoring points $A$ and $B$ almost does not change with the increase of the horizontal spacing of the lining, which indicates that the influence of the change of the tunnel spacing on the vibration velocity of the top of the lining face and the side wall can be ignored.

As for the monitoring point $\mathrm{C}$ on the lining side wall of the back blasting face and the monitoring point $\mathrm{D}$ at the bottom of the lining, it can be seen from Figure 11 that the vibration velocity of the monitoring point $\mathrm{C}$ is lower than 


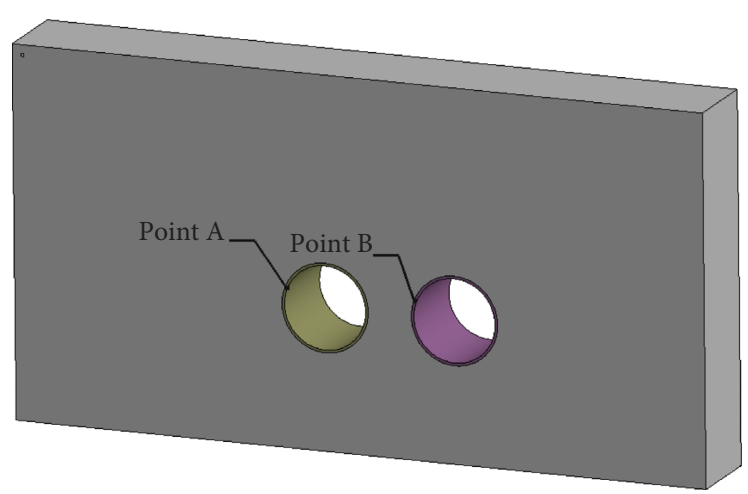

FigURE 6: Layout of monitoring points.

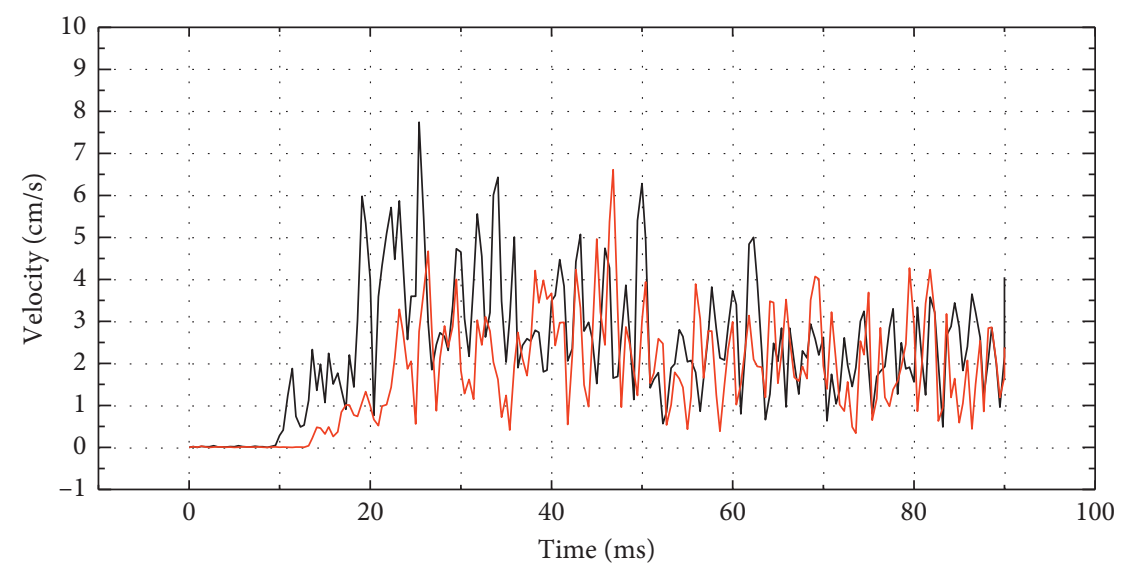

— Point A

— Point B

FIGURE 7: Velocity time-history curve of monitoring points.
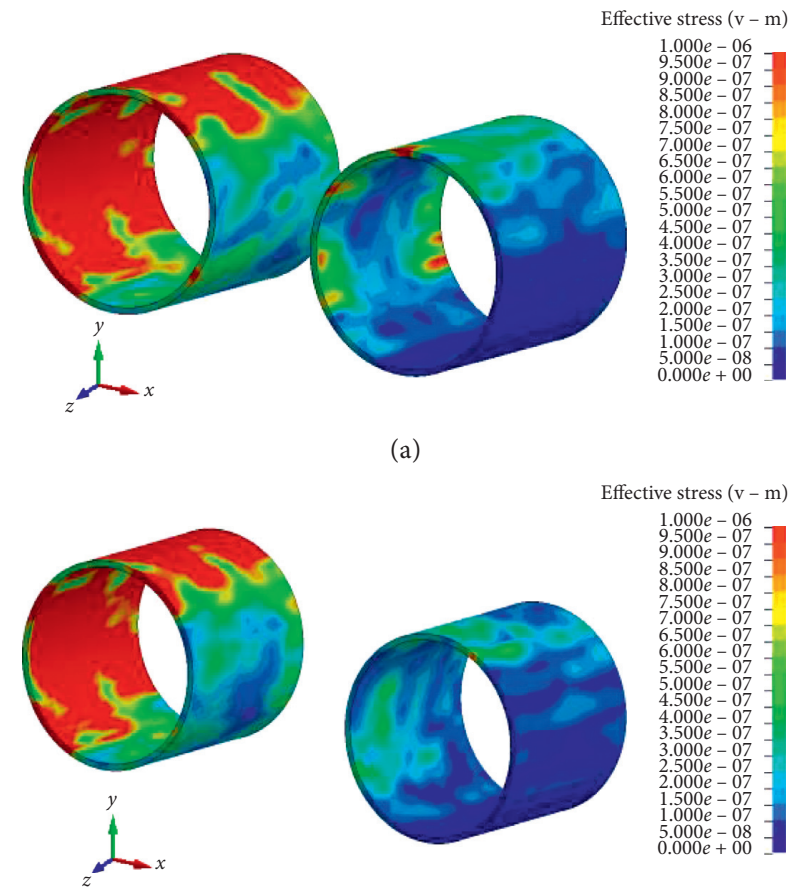

(a)

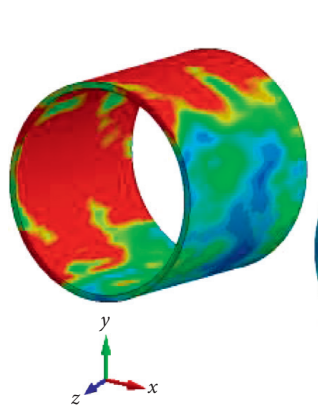

Effective stress $(v-m)$

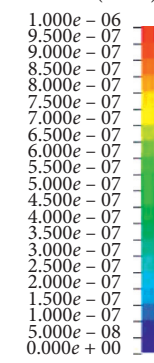

(c)

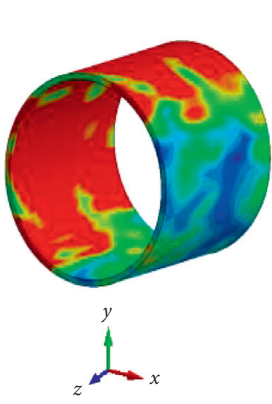

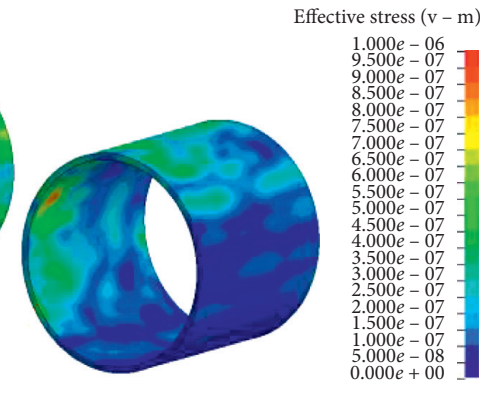

(b)

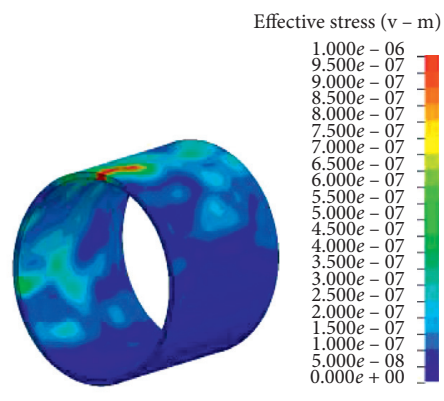

(d)

Figure 8: Continued. 

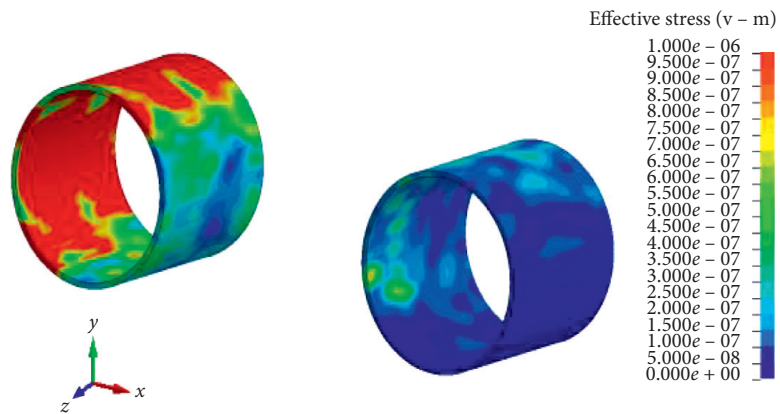

(e)

FIgURE 8: Equivalent stress nephogram of lining under condition 1 at $t=20 \mathrm{~ms}$ (Mbar). (a) A1. (b) A2. (c) A3. (d) A4. (e) A5.

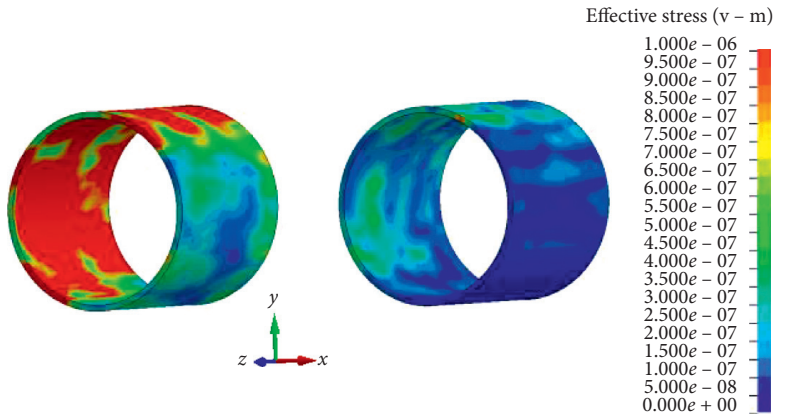

(a)

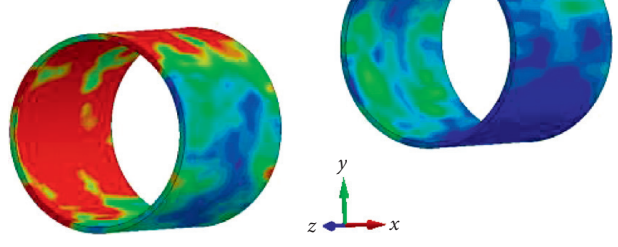

(c)

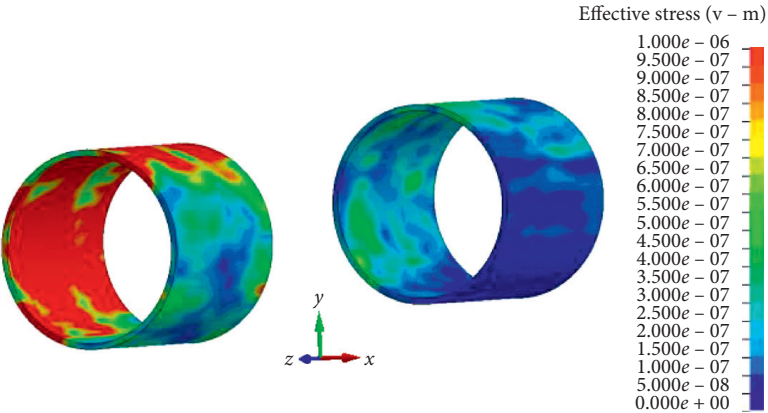

(b)

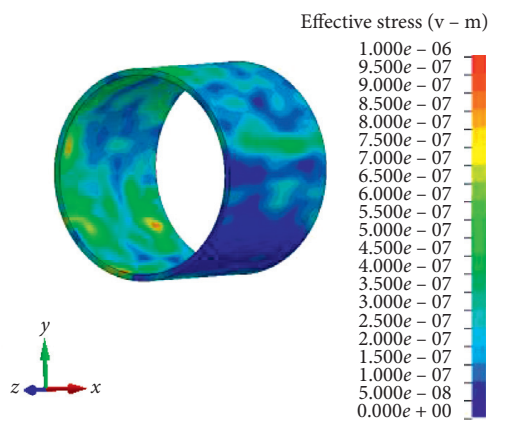

(d)
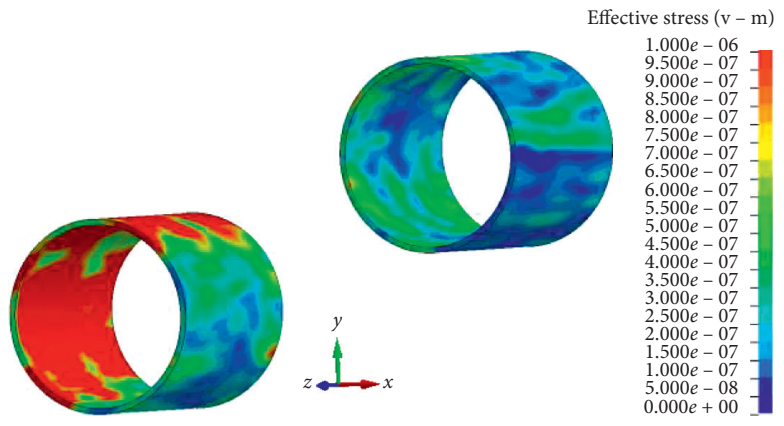

(e)

FIgURE 9: Equivalent stress nephogram of lining under condition 2 at $t=20 \mathrm{~ms}$ (Mbar). (a) A3. (b) B3. (c) C3. (d) D3. (e) E3.

that of the monitoring point $\mathrm{D}$, and with the increase of the horizontal clear distance of the tunnel, the vibration velocity of the monitoring points $\mathrm{C}$ and $\mathrm{D}$ decreases significantly. For the monitoring point $\mathrm{C}$ on the back blasting face, with the increase of the horizontal clear distance of the lining, the vibration velocity of the monitoring point $\mathrm{C}$ decreases from $6.4 \mathrm{~cm} / \mathrm{s}$ to $4.7 \mathrm{~cm} / \mathrm{s}$, and the peak velocity decreases by about $26.5 \%$. For point $\mathrm{D}$ at the bottom of back blasting surface, 


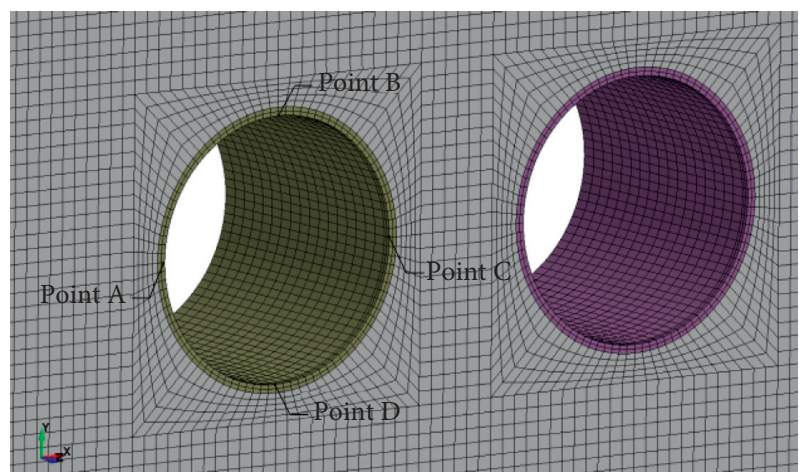

FIGURE 10: Layout of monitoring points.

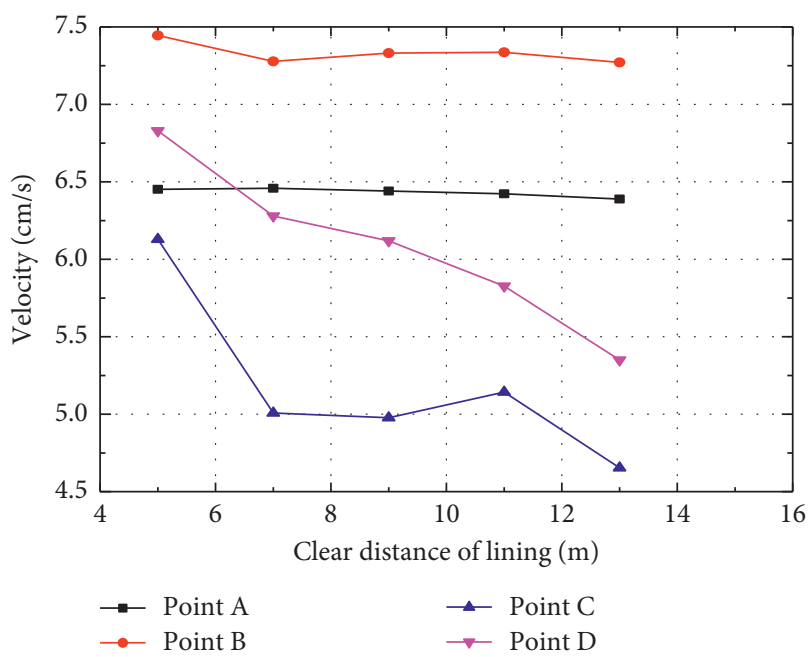

FIGURE 11: Relationship curve between monitoring points speed and horizontal clear distance of tunnel.

the vibration velocity of point $\mathrm{D}$ decreases from $6.7 \mathrm{~cm} / \mathrm{s}$ to $5.3 \mathrm{~cm} / \mathrm{s}$ with the increase of horizontal clear distance of lining, and the peak velocity decreases by about $20.9 \%$.

Figures 12-14 are the curves of the relationship between the equivalent stress of the monitoring point and the horizontal clear distance of the tunnel, the relationship between the stress of the monitoring point in the $X$-direction and the horizontal clear distance of the tunnel, and the relationship between the stress of the monitoring point in the $Y$-direction and the horizontal clear distance of the tunnel, respectively. It can be seen from Figure 12 that, similar to the variation law of velocity monitoring point, the peak value of equivalent stress of lining side wall monitoring point $\mathrm{A}$ and lining top point $B$ on the blast facing face does not change with the increase of horizontal spacing of lining. The peak value of equivalent stress of monitoring point $\mathrm{B}$ is about $0.42 \mathrm{MPa}$, and that of monitoring point $\mathrm{A}$ is about $0.36 \mathrm{MPa}$. The peak value of equivalent stress at point $\mathrm{A}$ is reduced by about $14 \%$.

For monitoring point $\mathrm{C}$ on lining side wall of back blasting face and monitoring point $\mathrm{D}$ on lining bottom, from the overall analysis of Figure 12, it can be seen that with the increase of horizontal spacing of tunnel, the equivalent stress of monitoring point decreases on the whole. For point $\mathrm{C}$, the peak value of equivalent stress decreases from $0.3 \mathrm{MPa}$ to

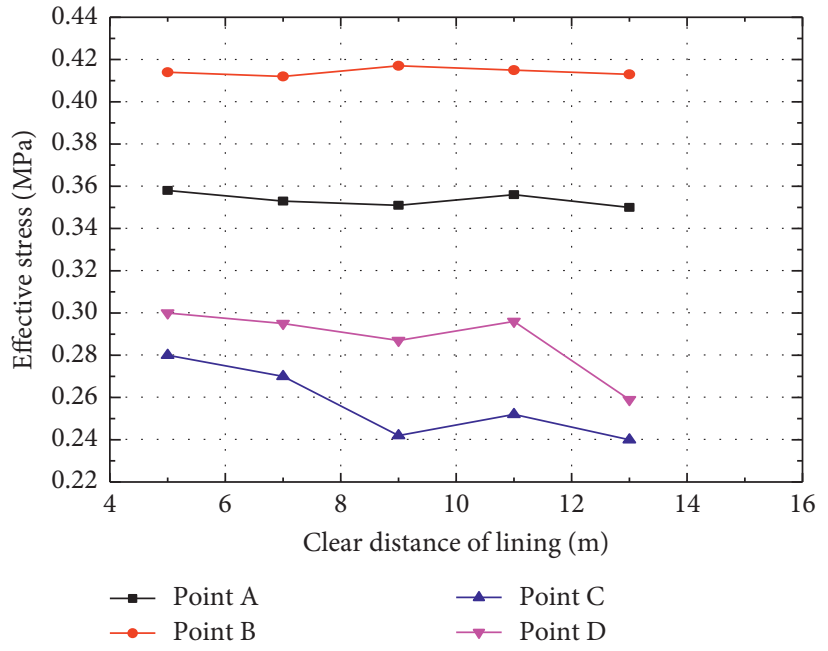

FIGURE 12: Relationship curve between equivalent stress of monitoring point and horizontal clear distance of tunnel.

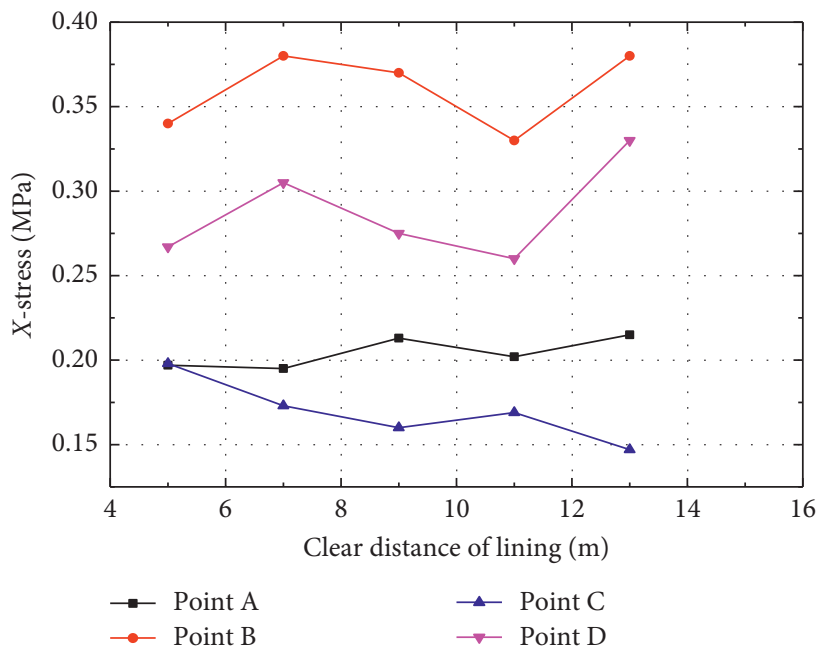

Figure 13: Relationship curve between $X$-direction stress of monitoring points and horizontal clear distance of tunnel.

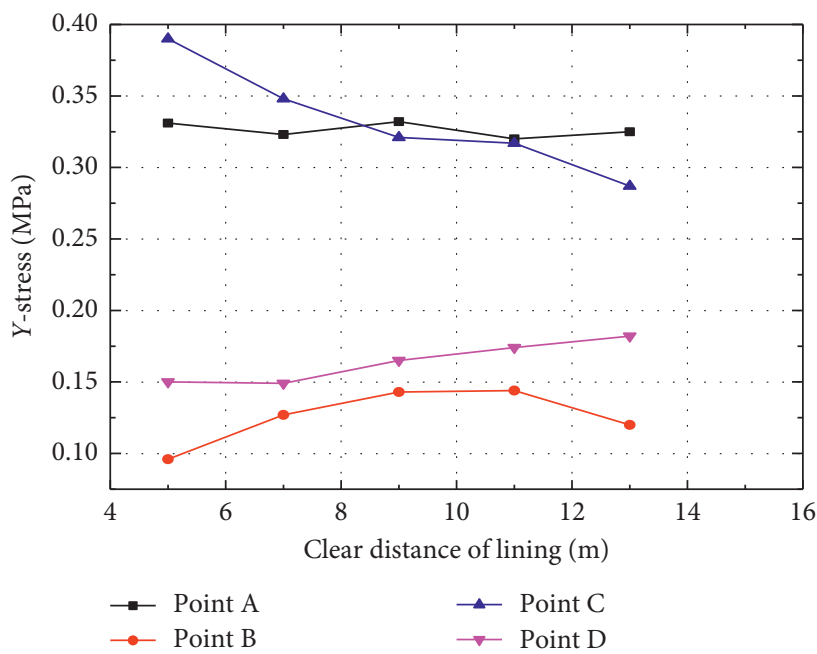

FIgURE 14: Relationship curve between $Y$-direction stress of monitoring points and horizontal clear distance of tunnel. 
$0.27 \mathrm{MPa}$, and the peak value of equivalent stress decreases by about $10 \%$. For point $\mathrm{D}$, the peak value of equivalent stress decreases from $0.28 \mathrm{MPa}$ to $0.24 \mathrm{MPa}$, and the peak value of equivalent stress decreases by about $14 \%$.

As for Figures 13 and 14, it can be seen from the analysis that no matter for the $X$-direction stress or $Y$-direction stress of the monitoring point, the peak stress of the monitoring point A has almost no obvious change. This is because although the refraction and diffraction effect of the rock stress wave between the two linings is produced, whose influence is mainly on the lining on the back blasting side, the influence on the monitoring point of the lining side wall on the blast facing side can be ignored. For point $\mathrm{C}$ on the blasted side, it can be seen from the analysis of Figures 13 and 14 that the stress components of $X$ and $Y$ are in a downward trend on the whole, while for the monitoring point $\mathrm{D}$ on the bottom of the lining, it can be seen that the stress component in the $Y$-direction has a slight increment with the increase of the net distance of the tunnel, and the stress peak value in the $Y$ direction increases from $0.15 \mathrm{MPa}$ to $0.18 \mathrm{MPa}$, an increase of about $20 \%$.

Figure 15 shows the relation between the velocity of the monitoring point and the height difference of the tunnel. It can be seen from Figure 15 that under the action of surface blasting, similar to the previous analysis, the peak value of vibration velocity at monitoring point $\mathrm{A}$ on the blast facing surface of lining side wall does not change significantly. For the monitoring point $\mathrm{B}$ on the blasting face of lining, with the increase of tunnel height difference, the peak value of vibration velocity increases. This is because as the right tunnel rises upward, which is more conducive to the reflection and superposition of stress wave, so the vibration velocity of measurement point $B$ increases. It can be seen that the vibration velocity of monitoring point B increases from $7.3 \mathrm{~cm} / \mathrm{s}$ to $7.7 \mathrm{~cm} / \mathrm{s}$, with an increase of about $5.5 \%$. When the height difference of lining is between 0 and $4 \mathrm{~m}$, the sensitivity of vibration velocity of side wall monitoring point $\mathrm{C}$ is low, and there is almost no significant change in vibration velocity. However, when the height difference is between 4 and $6 \mathrm{~m}$, the vibration velocity changes from $5 \mathrm{~cm} / \mathrm{s}$ to $5.5 \mathrm{~cm} / \mathrm{s}$, and the increase of vibration velocity in this interval is about $10 \%$. For point $\mathrm{D}$ at the bottom of the lining, the vibration velocity changes significantly with the increase of tunnel height difference. It can be seen that the vibration velocity of point D increases from $5.7 \mathrm{~cm} / \mathrm{s}$ to $7.1 \mathrm{~cm} / \mathrm{s}$, and the peak velocity increases by about $25 \%$.

Figures 16-18 are the curves of the relationship between the equivalent stress of the monitoring point and the height difference of the tunnel, the relationship between the $X$ direction stress of the monitoring point and the height difference of the tunnel, and the relationship between the $Y$ direction stress of the monitoring point and the height difference of the tunnel, respectively. It can be seen from Figure 16 that, with the increase of the tunnel height difference, the equivalent stress of points $\mathrm{A}$ and $\mathrm{B}$ on the blasting face remains stable, and the peak values of equivalent stress are about $0.36 \mathrm{MPa}$ and $0.43 \mathrm{MPa}$, respectively. For the back burst surface lining test point $\mathrm{C}$, the peak value

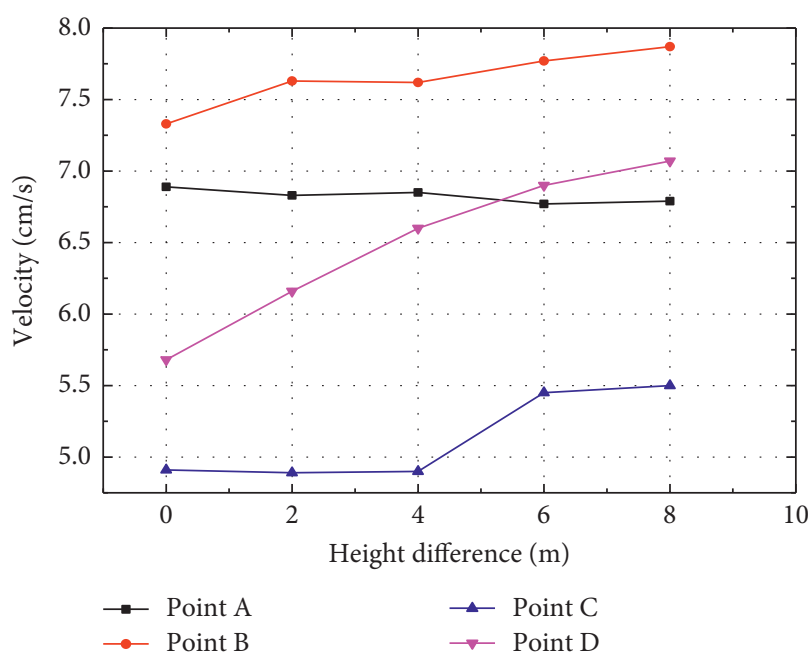

FIGURE 15: Relationship curve between monitoring points speed and horizontal height difference of tunnel.

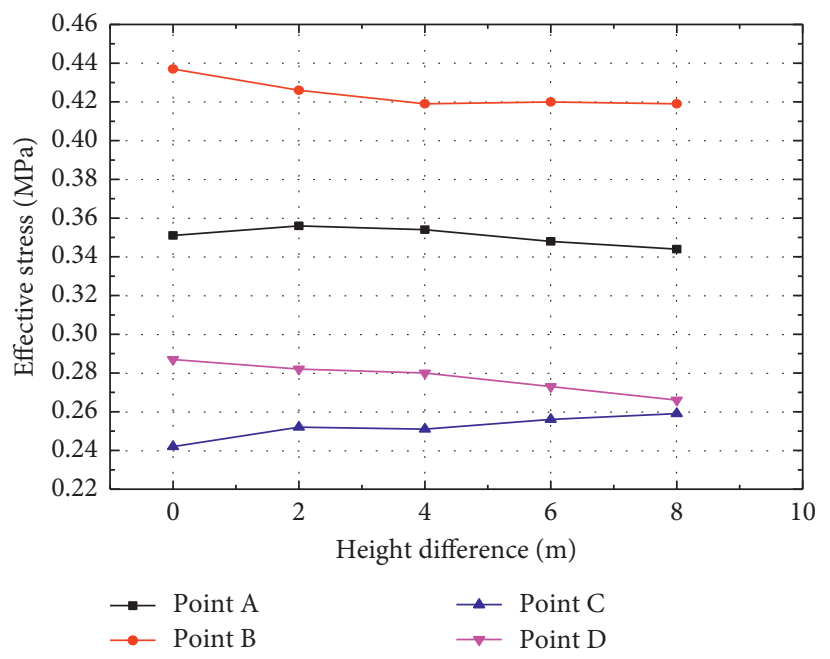

FIGURE 16: Relationship curve between equivalent stress of monitoring point and horizontal height difference of tunnel.

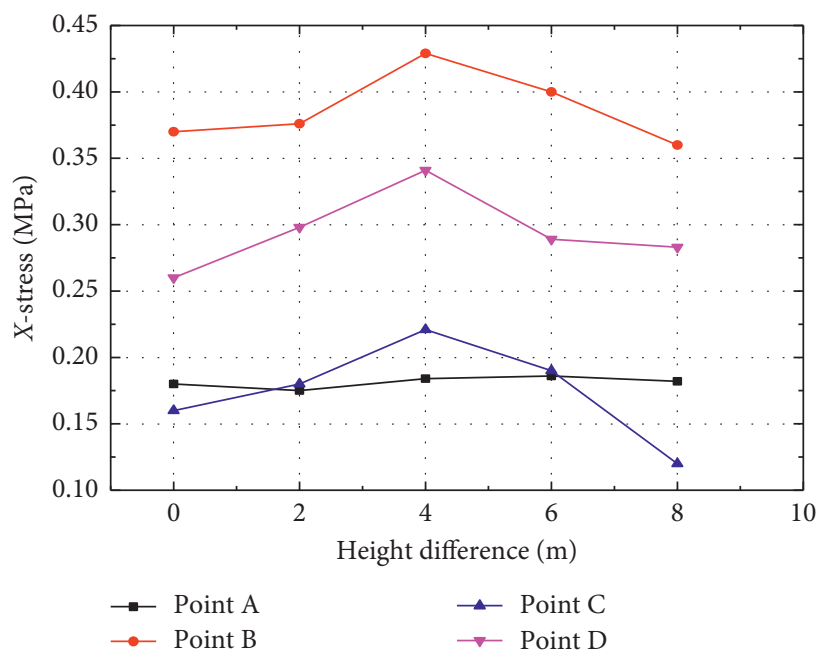

FIgURE 17: Relationship curve between the $X$-direction stress of monitoring points and tunnel height difference. 


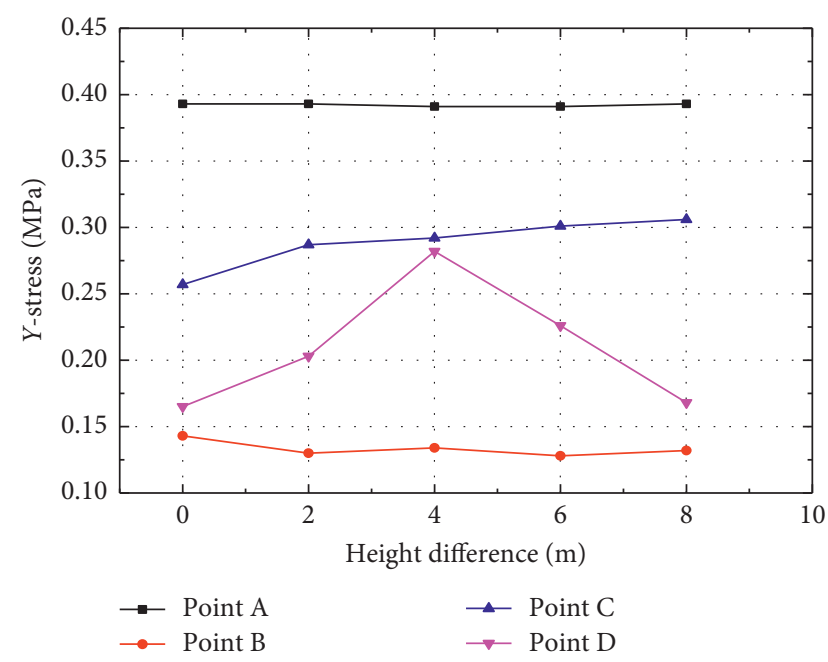

FIGURE 18: Relationship curve between the $Y$-direction stress of monitoring points and tunnel height difference.

of equivalent stress increases slightly with the increase of tunnel height difference, and the peak value of equivalent stress increases from $0.24 \mathrm{MPa}$ to $0.26 \mathrm{MPa}$, with an increase of about $8.3 \%$. For the back blasting face lining monitoring point $\mathrm{D}$, with the increase of tunnel height difference, the peak value of equivalent stress of point $D$ presents a small downward trend, and the peak value of equivalent stress decreases from $0.29 \mathrm{MPa}$ to $0.27 \mathrm{MPa}$, with a decrease of about $6.9 \%$. As for the $X$-direction stress component of the monitoring points, it can be seen from the analysis of Figure 17 that except for point A on the blasting face, the $X$ direction stress component of the other monitoring points increases first when the height difference of the lining is $0 \sim 4 \mathrm{~m}$ and then decreases when the height difference is about $4 \sim 8 \mathrm{~m}$. It shows that the reflected shock wave has the greatest influence on the $X$-direction stress component of the monitoring point on the back blasting surface of the left tunnel when the height difference of the adjacent tunnel is $4 \mathrm{~m}$ and the horizontal clear distance is constant. It can be seen from Figure 18 that the peak value of the $Y$-direction stress at the monitoring point $\mathrm{B}$ on the blasting face of the lining decreases slowly with the increase of the tunnel height difference, while for the monitoring point $\mathrm{C}$ on the blasting face of the lining, the component of the $Y$-direction stress decreases slightly with the increase of the tunnel height difference.

Figure 19 is the layout of the monitoring point path of the back burst surface of the left lining. Figures 20 and 21 show the relationship between the displacement along the path (along the negative direction of $Z$ ) of the horizontal net distance and the tunnel height difference $(t=31 \mathrm{~ms})$, respectively. It can be seen from the figure that the displacement of the lining monitoring point is decreasing along the path direction as a whole. It can also be seen that the displacement of the monitoring points of condition $1, \mathrm{~A} 1$ and A5 is larger than A2, A3, and A4, which shows that the variation of displacement of the monitoring points is not very significant due to the lining spacing. For condition 2 , it can be seen from Figure 21 that with the increase of the

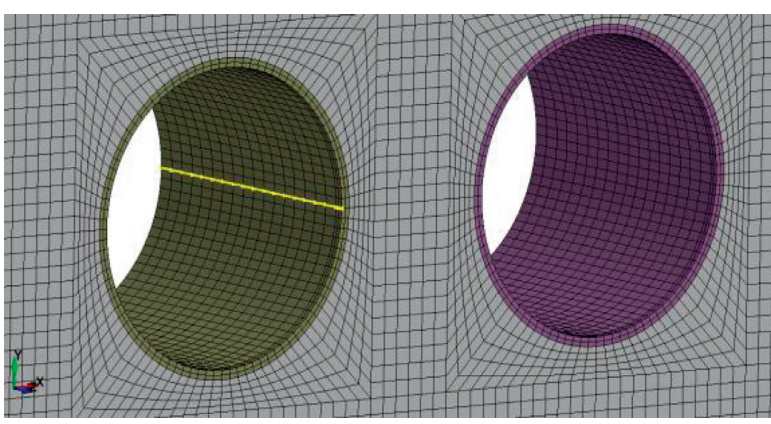

FIgURE 19: Path setting of lining monitoring points.

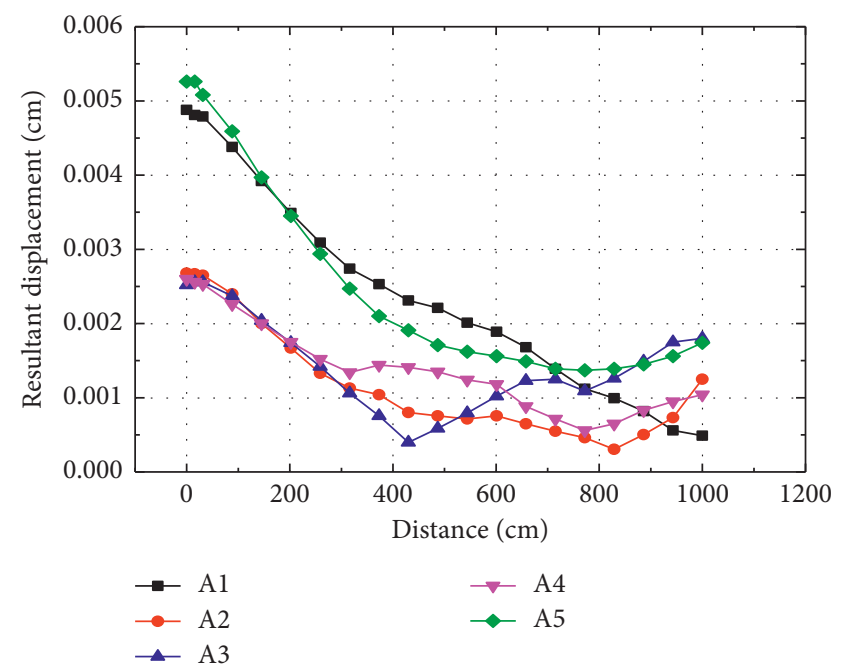

FIGURE 20: Variation of displacement of lining monitoring points along the path in case 1 .

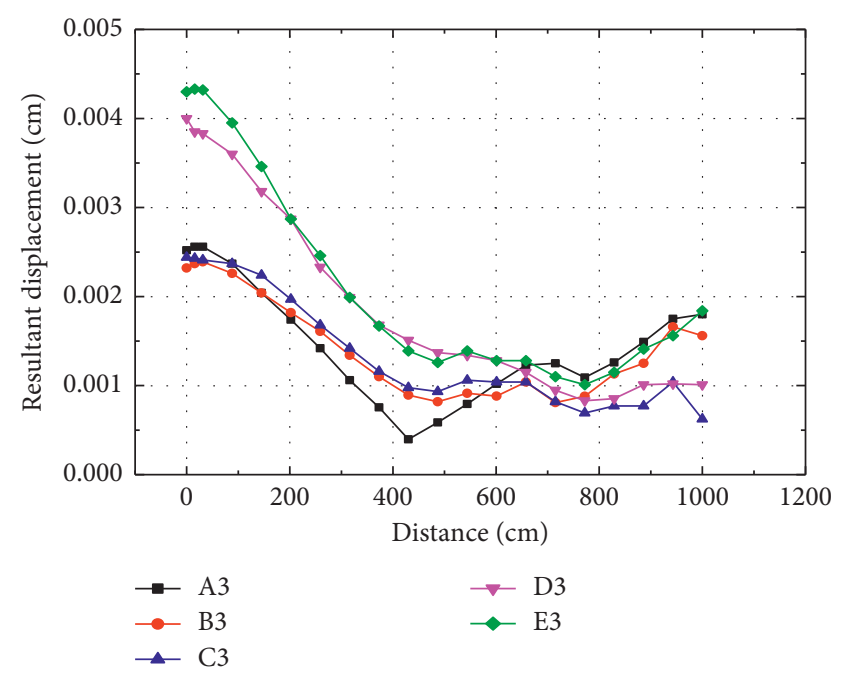

FIGURE 21: Variation of displacement of lining monitoring points along the path in case 2 .

tunnel height difference, the displacement of the monitoring point increases with the increase when the path length is less than $4 \mathrm{~m}$. In addition, the displacement increases obviously in the interval with the tunnel height difference of 4-6 m. 


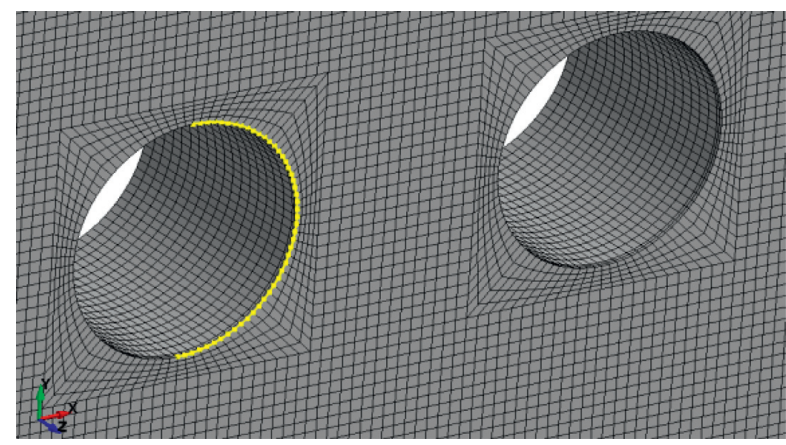

Figure 22: Path setting of tunnel rock mass monitoring points.

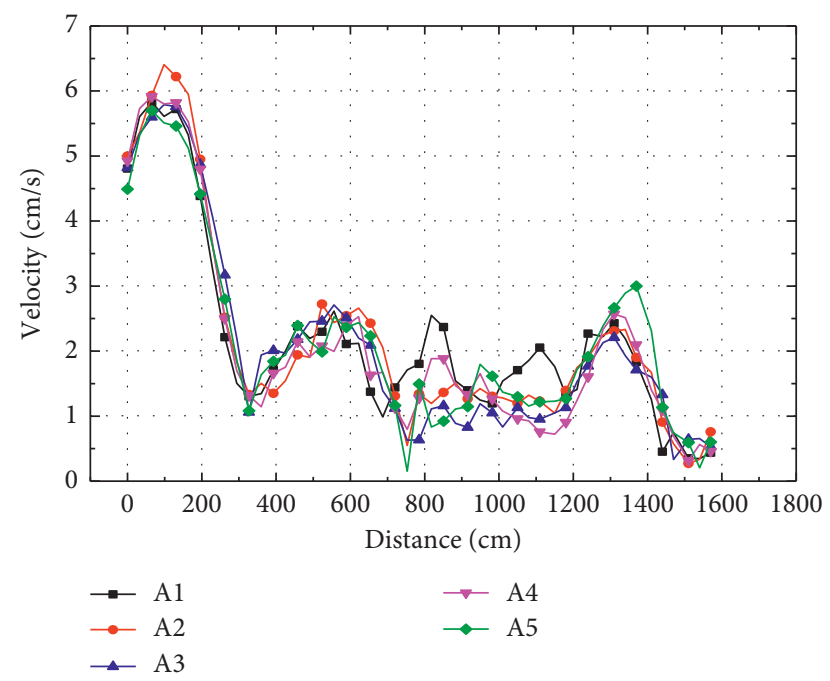

FIGURE 23: Variation velocity of lining monitoring points along the path in case 1.

Taking the initial point of the path (distance $=0$ ) as an example, the displacement of the monitoring point under $\mathrm{C} 3$ condition (height difference $=4 \mathrm{~m}$ ) is about $0.0025 \mathrm{~cm}$. The displacement of the monitoring point is about $0.004 \mathrm{~cm}$ under D3 condition (height difference $=6 \mathrm{~m}$ ), which is about $60 \%$ higher than that of the other.

Figure 22 is the path layout of rock monitoring points. The monitoring points are arranged clockwise along the $z$ axis. It can be seen that the variation law of the vibration velocity along the path of the monitoring points the same no matter in condition 1 or condition 2. The vibration velocity of the tunnel top reaches the peak at about $100 \mathrm{~cm}$ along the path, rather than just above the top of the tunnel, as shown in Figures 23 and 24. It can also be seen that the lowest vibration velocity is at the bottom of the tunnel. It can be seen from the dispersion degree of the vibration velocity value of two curves that the dispersion degree of condition 1 will be higher, which indicates that the change of the horizontal spacing of the tunnel will have more significant influence on the vibration velocity of each monitoring point than the change of the tunnel height difference.

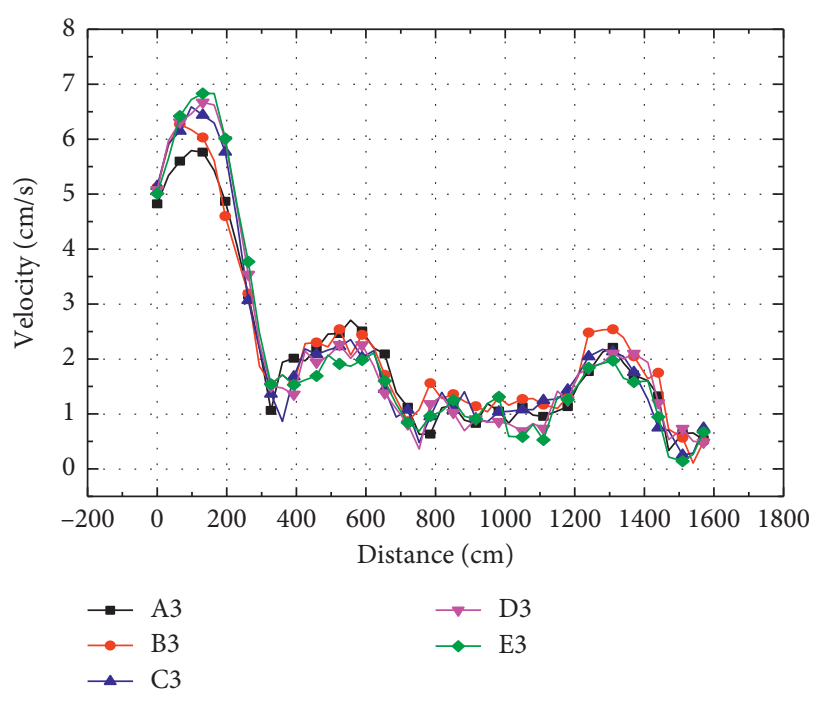

FIGURE 24: Variation velocity of lining monitoring points along the path in case 2 .

\section{Conclusions}

Based on LS-DYNA 3D nonlinear finite element software, a full coupling model of TNT explosive-surrounding rocklining structure-air is established. Lagrange algorithm is used for lining and rock mass materials. Euler algorithm is used for air and explosive materials. The nonlinear coupling between Euler fluid domain and Lagrange structure domain is realized by ALE multimaterial fluid structure coupling algorithm. By controlling the clear distance and height difference of double-line tunnel, a variety of numerical simulation cases are formulated. The dynamic response characteristics of double-line tunnel under different conditions and surface explosion load are systematically studied. The main conclusions are as follows:

Under the action of surface blasting, the influence of the tunnel clear distance and height difference on the dynamic response characteristics of the lining presents a nonlinear variation law except for the monitoring point $\mathrm{A}$ on the blasting face.

The peak velocity of monitoring points $\mathrm{A}$ and $\mathrm{B}$ on the blast facing surface hardly changes with the increase of the horizontal spacing of the lining, indicating that the influence of the change of the tunnel spacing on the vibration velocity of the top and side walls of the blast facing surface of the lining can be ignored. For point $\mathrm{C}$ on the side wall of back blasting face, the peak velocity of point $\mathrm{C}$ decreases about $26.5 \%$ with the increase of horizontal clear distance of lining. For point $\mathrm{D}$ at the bottom of back blasting face, the peak velocity of point $\mathrm{D}$ decreases about $20.9 \%$ with the increase of horizontal clear distance of lining. With the increase of the horizontal distance of the tunnel, the equivalent stress of the measuring points decreases on the whole.

With the increase of the height difference between adjacent tunnels, the peak value of vibration velocity of lining monitoring point $\mathrm{B}$ increases, which is more conducive to 
the reflection and superposition of stress waves due to the upward elevation of the right tunnel. When the height difference between adjacent tunnels is $4 \mathrm{~m}$, the reflected shock wave has the greatest influence on the $X$-direction stress component of the measuring points on the back blasting surface of the left tunnel. When the tunnel height difference is about 4 6 meters, the vibration velocity and displacement of monitoring point $\mathrm{C}$ on the back blasting side will change abruptly, and the variation range of vibration velocity is about $25 \%$, while the variation range of displacement is about $60 \%$.

\section{Data Availability}

The data are available and explained in this article; readers can access the data supporting the conclusions of this study.

\section{Disclosure}

The authors would like to declare that the work described herein is original research and has not been previously published elsewhere.

\section{Conflicts of Interest}

The authors declare that they have no conflicts of interest regarding the publication of this paper.

\section{Acknowledgments}

The authors gratefully acknowledge the funds provided by Shanxi Provincial Science and Technology Program ([2018] 1056) and Langfang Key Technology Research and Development Program of China (Grant no. 2020013039).

\section{References}

[1] A. Eitzenberger, Wave Propagation in Rock and the Influence of Discontinuities, Luleå University of Technology, Luleå, Sweden, 2012.

[2] Y. K. Wu, H. Hao, Y. X. Zhou, and K. Chong, "Propagation characteristics of blast-induced shock waves in a jointed rock mass," Soil Dynamics and Earthquake Engineering, vol. 17, no. 6, pp. 407-412, 1998.

[3] J. Yang, J. Cai, C. Yao, and P. Li, "Comparative study of tunnel blast-induced vibration on tunnel surfaces and inside surrounding rock," Rock Mechanics and Rock Engineering, vol. 52, no. 11, pp. 1-15, 2019.

[4] Q. Liang, J. Li, D. Li, and E. Ou, "Effect of blast-induced vibration from new railway tunnel on existing adjacent railway tunnel in xinjiang, China," Rock Mechanics and Rock Engineering, vol. 46, no. 1, pp. 19-39, 2013.

[5] Z. Mohammad and M. Rehan Sadique, "The response of rock tunnel when subjected to blast loading: finite element analysis," Engineering Reports, vol. 3, no. 2, 2020.

[6] J. B. Liu, Q. S. Yan, and J. Wu, "Analysis of blast wave propagation inside tunnel," Transactions of Tianjin University, vol. 14, no. 5, 2008.

[7] V. R. Feldgun, A. V. Kochetkov, Y. S. Karinski, and D. Z. Yankelevsky, "Internal blast loading in a buried lined tunnel," International Journal of Impact Engineering, vol. 35, no. 3, 2007.
[8] G. Yang, G. Wang, W. Lu, Y. Peng, and M. Chen, "Damage assessment and mitigation measures of underwater tunnel subjected to blast loads," Tunnelling and Underground Space Technology incorporating Trenchless Technology Research, vol. 94, no. 1, 2019.

[9] S. Koneshwaran, D. P. Thambiratnam, and C. Gallage, "Blast response of segmented bored tunnel using coupled SPH-fe method," Structure, vol. 2, no. 1, pp. 58-71, 2015.

[10] F. Wu, H. Zhang, Q. Zou, C. Li, J. Chen, and R. Gao, "Viscoelastic-plastic damage creep model for salt rock based on fractional derivative theory," Mechanics of Materials, vol. 150, no. 1, Article ID 103600, 2020.

[11] Y. Wang, W. K. Feng, R. L. Hu, and C. H. Li, "Fracture evolution and energy characteristics during marble failure under triaxial fatigue cyclic and confining pressure unloading (FC-CPU) conditions," Rock Mechanics and Rock Engineering, vol. 54, no. 5, pp. 799-818, 2021.

[12] Q. Wang, Y. Wang, M. He et al., "Experimental research and application of automatically formed roadway without advance tunneling," Tunnelling and Underground Space Technology, vol. 114, no. 3, Article ID 103999, 2021.

[13] Q.-X. Meng, W.-Y. Xu, H.-L. Wang, X.-Y. Zhuang, W.-C. Xie, and T. Rabczuk, "DigiSim - an open source software package for heterogeneous material modeling based on digital image processing," Advances in Engineering Software, vol. 148, no. 3, Article ID 102836, 2020.

[14] C. Zhu, M. C. He, M. Karakus, X.-H. Zhang, and Z. Guo, “The collision experiment between rolling stones of different shapes and protective cushion in open-pit mines," Journal of Mountain Science, vol. 18, no. 5, pp. 1391-1403, 2021.

[15] C. Zhu, M. C. He, M. Karakus, X. H. Zhang, and Z. G. Tao, "Numerical simulations of the failure process of anaclinal slope physical model and control mechanism of negative Poisson's ratio cable," Bulletin of Engineering Geology and the Environment, vol. 80, no. 7, pp. 3365-3380, 2021.

[16] A. Li, F. Dai, Y. Liu, H. Du, and R. Jiang, "Dynamic stability evaluation of underground cavern sidewalls against flexural toppling considering excavation-induced damage," Tunnelling and Underground Space Technology, vol. 112, Article ID 103903, 2021.

[17] Livermore Software Technology Corporation (LSTC), LSDYNA Keyword User's Manual Version R 10.0, Livermore Software Technology Corporation, Livermore, CA, USA, 2017.

[18] M. Larcher and F. Casadei, "Explosions in complex geometries-a comparison of several approaches," International Journal of Protective Structures, vol. 1, no. 2, 2010.

[19] X. Huo, X. Shi, X. Qiu et al., "Rock damage control for largediameter-hole lateral blasting excavation based on charge structure optimization," Tunnelling and Underground Space Technology, vol. 106, Article ID 103569, 2020.

[20] J. O. Hallquist, LS-DYNA Theoretical Manual, Livemore Software Technology, Livemore, CA, USA, 1998.

[21] H. R. Yadav, Geotechnical Evaluation and Analysis of Delhimetro Tunnels, Indian Institute of Technology (IIT), Delhi, India, 2005. 